\title{
Characterisation of Prussian blue modified screen-printed electrodes for thiol detection
}

\author{
Francesco Ricci ${ }^{\mathrm{a}, *}$, Fabiana Arduini ${ }^{\mathrm{a}}$, Aziz Amine ${ }^{\mathrm{b}}$, \\ Danila Moscone ${ }^{\text {a }}$, Giuseppe Palleschi ${ }^{\text {a }}$ \\ a Dipartimento di Scienze e Tecnologie Chimiche, Università "Tor Vergata", Via della Ricerca Scientifica, 00133 Roma, Italy \\ ${ }^{\mathrm{b}}$ Faculté de Sciences et Techniques de Mohammadia, B.P. 146, Mohammadia, Morocco
}

Received 29 July 2003; received in revised form 19 September 2003; accepted 26 September 2003

\begin{abstract}
The electrocatalytic behaviour of Prussian blue towards thiol oxidation was thoroughly investigated. Cyclic voltammetry experiments performed in thiol solution showed the classical shape of a mediated redox system. The current due to thiol-mediated oxidation was then evaluated in batch amperometric mode at $+200 \mathrm{mV}$ vs. $\mathrm{Ag} \mid \mathrm{AgCl}$. Many thiocompounds were investigated and their different reactivities were discussed. Thiocholine and cysteamine were found to give the best results in terms of LOD (i.e., $5 \times 10^{-6}, 10^{-6} \mathrm{~mol}^{-1}$, respectively) and linear range $\left(5 \times 10^{-6}-5 \times 10^{-4}, 10^{-6}-10^{-4} \mathrm{~mol}^{-1}\right.$, respectively). Two applications are also proposed, one involving the measurement of thiocholine as a mean for pesticide detection, and the other being an electrochemical alternative to Ellman's test for total thiol estimation.
\end{abstract}

(C) 2003 Elsevier B.V. All rights reserved.

Keywords: Prussian blue; Thiols; Electrochemical detection; Pesticide; Chemically modified electrodes; Screen-printed electrodes

\section{Introduction}

Non-protein thiols (i.e., cysteine, glutathione, homocysteine) are critical cellular components that play numerous important roles in metabolism as key extracellular reducing agents [1], critical substrates for protein synthesis [2], and detoxificants of free radicals and peroxides [3]. Other thiols are used for the synthesis of drugs such as $\mathrm{N}$-acetylcysteine, penicillamine and cysteamine $[4,5]$. Their measurement is thus considered a primary goal in analytical chemistry. In recent years, the electrochemical detection of thiols has been a matter of investigation for many research groups. The major problem related to the electrochemical detection of thiols is the high overpotential required at most conventional electrode surfaces; thus the use of chemically modified electrodes has been proposed for amperometric detection of thiols at low applied potentials [6-9]. In

\footnotetext{
${ }^{*}$ Corresponding author. Tel.: +00390672594403; fax: +00390672594328 .

E-mail address: francesco.ricci@uniroma2.it (F. Ricci).
}

this respect, the electrochemical determination of sulfhydryl compounds with cobalt phthalocyanine has been fully and extensively studied [10-12]. The use of hexacyanoferrate modified electrodes has also been demonstrated to be suitable for achieving an improved signal from thiol oxidation at relatively low potentials [13-16]. In this respect, indium [17], cobalt [18], zinc [14] and copper hexacyanoferrates [17] have been fully characterised and investigated.

Relative to the other hexacyanoferrates, the use of Prussian blue (ferric hexacyanoferrate) as a mediator for the electrochemical detection of thiols has found only a limited use [19]. Prussian blue has in fact been used for its catalytic activity towards hydrogen peroxide reduction [20-24], and in this regard is used primarily for the construction of hydrogen peroxide probes or in the assembly of oxidase-enzyme based biosensors [25-28].

For these applications Prussian blue modification has been fully tested with many electrode materials such as glassy carbon [29], graphite [30], carbon paste [22] and glassy carbon paste [27]. Recently, an application of PB with screen-printed electrodes (SPEs) has been developed 
by our group [23]. The screen-printing technology has found wide use for analytical applications because of its low cost which makes possible mass production of electrodes and the development of practical "in situ" analysis [31-34].

In this paper, we report on the use of $\mathrm{PB}$ as a catalyst for the oxidation of thiols and, for the first time to our knowledge, an extensive study of the electrocatalytic response of PB modified SPE to many thiol compounds is presented for the clarification of the parameters affecting the catalytic mechanism.

Two applications are also proposed. In the first one the ability of screen-printed electrodes modified with PB to oxidise cysteamine is utilised for the electrochemical detection of the most important thiols. In the second application, the response due to thiocholine at the $\mathrm{PB}$ modified electrode is used to assemble a pesticide sensor for organophosphorous and carbamate pesticides.

\section{Experimental}

\subsection{Apparatus}

Amperometric measurements were carried out using a VA 641 amperometric detector (Metrohm, Herisau, Switzerland), connected to a X-t recorder (L250E, Linseis, Selb, Germany).

Cyclic voltammetry (CV) was performed using an Autolab electrochemical system (Eco Chemie, Utrecht, The Netherlands) equipped with a PGSTAT-12 and GPES software (Eco Chemie, Utrecht, The Netherlands).

\subsection{Electrodes}

Screen-printed electrodes were produced with a 245 DEK (Weymouth, England) screen-printing machine. Graphite-based ink (Elettrodag 421) from Acheson Italiana (Milan, Italy) was used to print the working electrode. The substrate was a flexible polyester film (Autostat HT5) obtained from Autotype Italia (Milan, Italy). The printing procedure utilised has already been described in previous papers $[23,35]$. The electrodes were produced in foils of 20 . The diameter of the working electrode was $0.3 \mathrm{~cm}$ resulting in an apparent geometric area of $0.07 \mathrm{~cm}^{2}$. $\mathrm{An} \mathrm{Ag}|\mathrm{AgCl}| \mathrm{KCl}\left(3 \mathrm{~mol} \mathrm{l}^{-1}\right)$ electrode and a platinum electrode were used as reference and counter electrodes, respectively.

\subsection{Reagents}

All chemicals from commercial sources were of analytical grade.

All thiol solutions were prepared with $0.05 \mathrm{~mol} \mathrm{l}^{-1}$ phosphate buffer $+0.1 \mathrm{~mol} \mathrm{l}^{-1} \mathrm{KCl}, \mathrm{pH} 5.5$. The stan- dard solutions were made up daily in the same buffer. Before each measurement, the exact concentration of the thiol was evaluated using the spectrophotometric Elmann test based on the reaction between the thiol and DTNB (5,5'-dithiobis-(2-nitrobenzoic acid). For this purpose $900 \mu$ of a phosphate buffer solution $(0.05 \mathrm{~mol}$ $\left.1^{-1}\right), \mathrm{pH} 8.0$, was mixed with $100 \mu \mathrm{l}$ of a DTNB solution $\left(10^{-3} \mathrm{~mol}^{-1}\right)$. Then, the solution was spiked with $5 \times 10^{-5} \mathrm{~mol}^{-1}$ of thiol and the absorption was evaluated at $412 \mathrm{~nm}$.

Acetylcholinesterase (AChE) (EC 3.1.1.7, $244 \mathrm{U} / \mathrm{mg}$ ) was obtained from Sigma (St. Louis, MO). For $\mathrm{pH}$ measurements, a Britton-Robinson universal (4-12 pH) buffer $\left(0.05 \mathrm{~mol}^{-1}\right.$ of phosphate, acetate and borate sodium salts $+0.1 \mathrm{~mol} \mathrm{l}^{-1} \mathrm{KCl}$ ) was used. The $\mathrm{pH}$ was adjusted using $\mathrm{KOH}$ and $\mathrm{HCl}$.

\subsection{Preparation of PB modified screen-printed electrodes}

Prior to PB modification, SPEs were pre-treated in $0.05 \mathrm{~mol}^{-1}$ phosphate buffer $+0.1 \mathrm{~mol}^{-1} \mathrm{KCl}, \mathrm{pH} 7.4$, by applying a positive potential of $1.7 \mathrm{~V}$ for $3 \mathrm{~min}$. $\mathrm{PB}$ modification of SPEs was then accomplished by placing a drop (10 $\mu$ l total volume) of "precursor solution" onto the working electrode area. This solution was a mixture obtained by adding $5 \mu \mathrm{l}$ of $0.1 \mathrm{~mol} \mathrm{l^{-1 }}$ potassium ferricyanide $\left(\mathrm{K}_{3} \mathrm{Fe}(\mathrm{CN})_{6}\right)$ in $10 \mathrm{mmol}^{-1} \mathrm{HCl}$ to $5 \mu$ of 0.1 mol $1^{-1}$ ferric chloride in $10 \mathrm{mmol}^{-1} \mathrm{HCl}$. The drop was carefully applied exclusively on the working electrode area. The electrodes were shaken gently on an orbital shaker for $10 \mathrm{~min}$ and then rinsed with a few millilitres of $10 \mathrm{mmol}^{-1} \mathrm{HCl}$. The probes were then left for $90 \mathrm{~min}$ in an oven at $100{ }^{\circ} \mathrm{C}$ to obtain a more stable and active layer of Prussian blue.

The PB modified electrodes were stored dry at room temperature in the dark.

Prior to amperometric measurements, electrodes were treated for $7 \mathrm{~min}$ at $0.0 \mathrm{~V}$ vs. $\mathrm{Ag} \mid \mathrm{AgCl}$ in phosphate buffer solution.

\subsection{Thiol measurements}

Measurements of thiols were performed using amperometric batch analysis in a stirred phosphate buffer solution, $0.05 \mathrm{~mol} \mathrm{l}^{-1}+0.1 \mathrm{~mol} \mathrm{l}^{-1} \mathrm{KCl}, \mathrm{pH} 7.4(10 \mathrm{ml})$ with an applied potential of $+200 \mathrm{mV}$ vs. $\mathrm{Ag} \mid \mathrm{AgCl}$. When a stable baseline current was reached, the analyte was added and the response was recorded.

\subsection{Inhibition measurements}

Aldicarb and Paraoxon in aqueous solutions were used as standard pesticides for the acetylcholinesterase inhibition measurements. The thiocholine sensor was incubated in cholinesterase buffer solution with or without a given amount of pesticide for $10 \mathrm{~min}$. Fol- 
lowing that, acetylthiocholine $\left(2 \times 10^{-3} \mathrm{~mol} \mathrm{l}^{-1}\right)$ was added and the response due to the production of thiocholine by acetylcholinesterase was measured after 20 min. The degree of inhibition was calculated as the relative decrease of the thiocholine signal

$I=\left[\left(I_{0}-I_{i}\right) / I_{i}\right] \times 100 \%$,

where $I_{0}$ and $I_{i}$ are the sensor response in the absence and in the presence of pesticide, respectively.

\subsection{Thiol measurements using disulphide exchange reac- tion}

In the electrochemical procedure proposed in this paper for thiol measurements, the sensors were used in amperometric batch mode. The PB electrode was immersed in the working buffer. When a stable baseline current was obtained (at an applied potential $=200 \mathrm{mV}$ vs. $\mathrm{Ag} \mid \mathrm{AgCl}$ ), the desired concentration of a reduced thiol was added to the solution. After $1 \mathrm{~min}$, as soon as the current reached a new stable baseline, cystamine (RSSR), the oxidised form of cysteamine (RSH), was added at a concentration of $10^{-3} \mathrm{~mol} \mathrm{l}^{-1}$, and the current due to the formation of cysteamine was recorded.

\section{Results and discussion}

\subsection{Catalytic oxidation of thiocholine by Prussian blue}

Thiocholine has primarly been studied as a standard thiol because of its importance in environmental analysis. Determination of thiocholine is in fact usually carried out to evaluate the degree of inhibition of acetylcholinesterase, a target enzyme of pesticides, in order to achieve indirect organophsphorous and carbamate pesticide measurements.

The effect of PB modification on thiocholine oxidation at the SPE surface was first evaluated by performing voltammetric experiments. Fig. 1 compares the cyclic voltammograms of bare electrodes and PB modified electrodes in the presence and absence of $1 \mathrm{mM}$ thiocholine.

In the case of bare screen-printed electrodes, the oxidation of thiocholine starts at high potentials (ca. 400 $\mathrm{mV}$ ) and reaches a maximum at around $600-700 \mathrm{mV}$.

In the case of CVs recorded with $\mathrm{PB}$ modified electrodes in buffer solution (scan rate: $10 \mathrm{mV} / \mathrm{s}$ ), two characteristic peaks due to the oxidation and reduction of PB can be clearly observed. The small distance between peak potentials (i.e., $15 \mathrm{mV}$ ) and the ratio, close to one, of the cathodic to anodic currents indicates the typical behaviour of an electroactive species adsorbed on the electrode surface.

In the presence of $1 \mathrm{mM}$ thiocholine, the current due to $\mathrm{PB}$ oxidation starts increasing (with respect to that

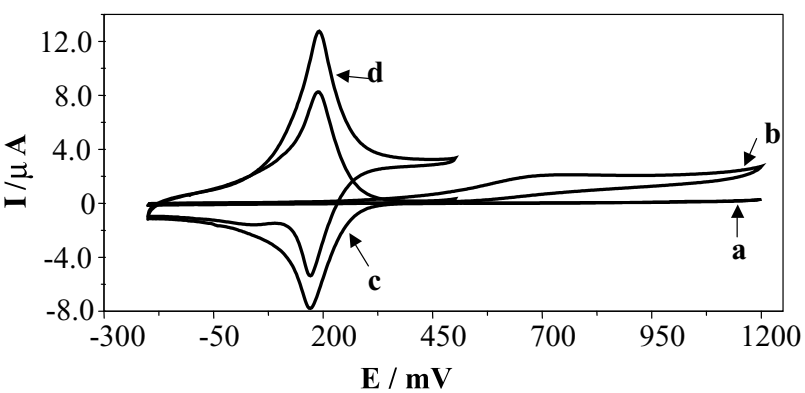

Fig. 1. Cyclic voltammograms revealing the catalytic oxidation of thiocholine at a PB modified SPE. Cyclic voltammograms obtained with unmodified electrodes are also shown. Scan rate: $10 \mathrm{mV} / \mathrm{s}$. 0.05 mol $1^{-1}$ phosphate buffer $+0.1 \mathrm{~mol}^{-1} \mathrm{KCl}$, pH 7.4: (a) unmodified electrode in phosphate buffer; (b) unmodified electrode in $1.0 \mathrm{mmol}^{-1}$ thiocholine; (c) PB modified electrode in phosphate buffer; (d) PB modified electrodes in $1.0 \mathrm{mmol}^{-1}$ thiocholine.

obtained in buffer solution) at ca. $100 \mathrm{mV}$ vs. $\mathrm{Ag} \mid \mathrm{AgCl}$ while, in the reverse scan, a decrease of the reduction current is observed, as expected in the case of a mediated electrochemical oxidation. The oxidation current observed in the presence of thiocholine seems, in fact, to appear in correspondence to the formation of the oxidised form of PB, suggesting a catalytic effect of such a mediator for the oxidation of thiocholine.

This result seems to demonstrate that $\mathrm{PB}$ has an electrocatalytic activity towards the oxidation of thiocholine. The generic reactions that occur on the electrode surface could be as follows:

$$
\begin{aligned}
& \mathrm{PB}_{\text {ox }}+\mathrm{RSH} \rightleftarrows \mathrm{PB}_{\text {red }}+\mathrm{RSSR} \\
& \mathrm{PB}_{\text {red }}+\text { electrode } \rightleftarrows \mathrm{PB}_{\text {ox }}+\text { electrode }
\end{aligned}
$$

According to Eq. (1), the injection of RSH causes an increase in concentration of the $\mathrm{PB}_{\text {red }}$ in the proximity of the electrode, resulting in an increase of the anodic peak current. By contrast, the cathodic peak is proportional to $\mathrm{PB}_{\mathrm{ox}}$ concentration, which is diminished at the electrode surface, by the reaction with thiol (RSH).

The catalytic thiol oxidation in the case of PB seems to be achieved with the redox centre active at around $+150 \mathrm{mV}$, and is attributable to the following reaction (Eq. (2)) [36]:

$$
\mathrm{Fe}_{4}^{\mathrm{III}}\left[\mathrm{Fe}^{\mathrm{II}}(\mathrm{CN})_{6}\right]_{3}+4 \mathrm{e}^{-}+4 \mathrm{~K}^{+} \rightleftarrows \mathrm{K}_{4} \mathrm{Fe}_{4}^{\mathrm{II}}\left[\mathrm{Fe}^{\mathrm{II}}(\mathrm{CN})_{6}\right]_{3}
$$

The oxidation of the thiol group then has to be ascribed, in this case, to the ferric ions present on the outer sphere of the PB lattice structure, which seems to have a catalytic effect on thiol oxidation. It should be stressed that in the case of the mediated oxidation of thiols with other hexacyanoferrates (i.e., Ni. Co, $\mathrm{Zn}, \mathrm{Cu}$ ), the oxidation is always attributed to the ferricyanide ions, which occurs in the range of $600-700 \mathrm{mV}$. In the case of PB, on the other hand, the current starts increasing at very low potentials (around $100 \mathrm{mV}$ ) where all the other 
hexacyanoferrate-based mediators commonly used to mediate the thiol oxidation are still not active. Thus, using PB modified electrodes, it might be possible to have a detectable signal due to thiocholine oxidation at lower applied potentials.

Since the anodic peak potential of $\mathrm{PB}$ is found at around $+150-200 \mathrm{mV}$, the potential to be applied at the electrode surface for thiol amperometric detection has been chosen in this range by amperometric batch analysis at different fixed potentials.

\subsection{Choice of the applied potential}

A current/applied potential plot, obtained with the PB modified electrodes in the presence of thiocholine $\left(0.05 \mathrm{mmol} \mathrm{l}^{-1}\right)$, is shown in Fig. 2. As expected, the amperometric response follows the behaviour of the oxidation current in the CVs. The oxidation current increased rapidly at potentials near $100 \mathrm{mV}$, reaching a relative maximum at around $200 \mathrm{mV}$. Up to $500 \mathrm{mV}$ no significant increase of the current was observed. In order

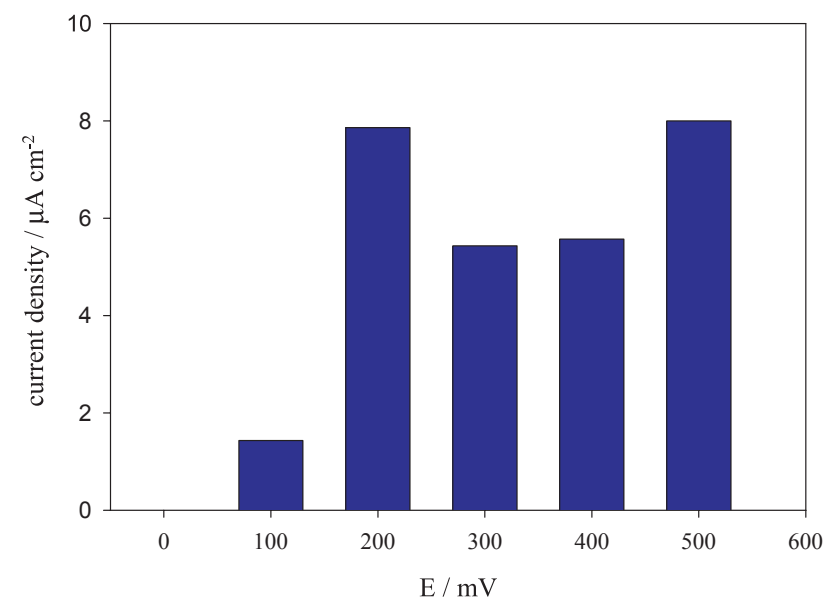

Fig. 2. Current density/applied potential plot of PB modified SPE. Potential range 0.0 to $+0.5 \mathrm{~V}$ vs. $\mathrm{Ag} \mid \mathrm{AgCl} .0 .05 \mathrm{~mol} \mathrm{l}^{-1}$ phosphate buffer $+0.1 \mathrm{~mol} \mathrm{l}^{-1} \mathrm{KCl}$, pH 7.4. Response for thiocholine solution $5 \times 10^{-5} \mathrm{~mol} \mathrm{1}^{-1}$. to compare the response of thiocholine with possible electroactive compounds, ascorbic acid was tested at the same applied potentials. At $200 \mathrm{mV}$ the current due to the ascorbic acid, injected into the solution at the same concentration as that of thiocholine, was of the same magnitude. At higher potentials, the current due to ascorbic acid quickly increased. At $500 \mathrm{mV}$ the ratio between the signal for ascorbic acid and that for thiocholine was almost 10 . On the basis of these results, $200 \mathrm{mV}$ was chosen as the optimum applied potential.

\subsection{Thiol oxidation by Prussian blue}

The electrocatalytic behaviour of PB towards thiocholine that was observed in cyclic voltammetry experiments appears promising for the detection of other chemically important thiol compounds of clinical importance, such as cysteamine, homocysteine or glutathione. The same cyclic voltammetry study carried out with thiocholine was then adopted for these compounds to discover whether a catalytic effect of Prussian blue could also be observed with other thiols.

Fig. 3 shows the cyclic voltammograms of PB modified SPEs obtained in the absence and in the presence of $10 \mathrm{mmol} \mathrm{l}^{-1}$ of each thiol. In the first cycle (Fig. 3(a)) it is possible to note that upon the addition of cysteamine, the anodic peak current is increased by about $300 \%$, while a decrease in the cathodic peak current of about $50 \%$ is seen, indicating a catalytic reduction reaction which can again be attributed to Prussian blue and explained in terms of Eq. (1). Fig. 3(b) shows cyclic voltammograms obtained in the absence and in the presence of homocysteine. In this case, upon the addition of homocysteine, a smaller increase $(30 \%)$ in the anodic current, with a corresponding decrease $(20 \%)$ in the cathodic current, is observed. By contrast, when glutathione was added (Fig. 3(c)), no apparent change in the shape of the CV was observed. On the basis of these results it appears that the catalytic behaviour of $\mathrm{PB}$ towards thiol oxidation depends greatly on the type of
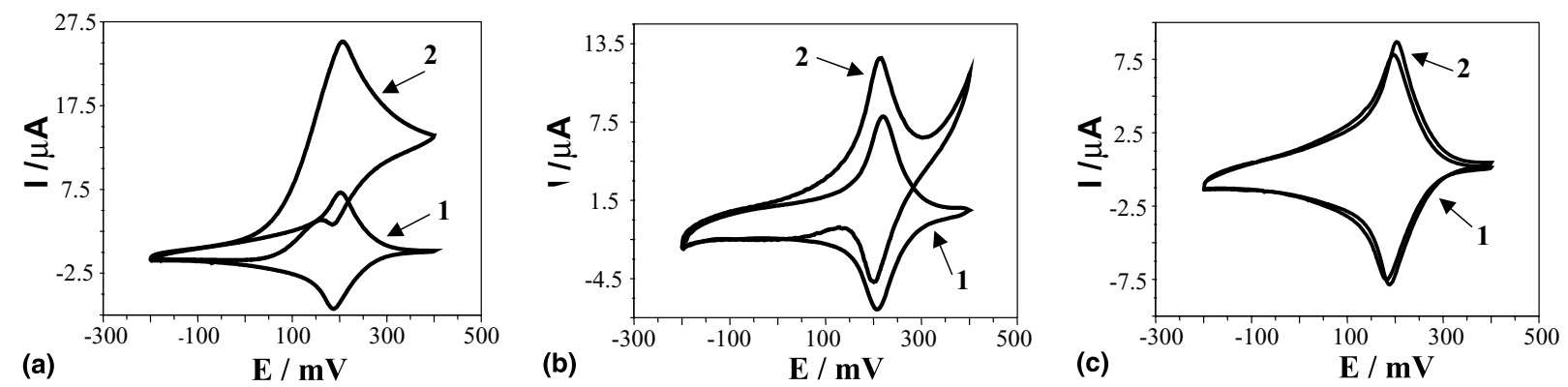

Fig. 3. Cyclic voltammograms of cysteamine, homocysteine and glutathione at PB modified SPE. Scan rate: $10 \mathrm{mV} / \mathrm{s}$. Phosphate buffer $0.05 \mathrm{~mol}$ $\mathrm{l}^{-1}+\mathrm{KCl} 0.1 \mathrm{~mol} \mathrm{l}^{-1}$, pH 7.4. Cyclic voltammograms obtained in absence (1) and in presence (2) of $10 \mathrm{mmol} \mathrm{l}^{-1}$ of (a) cysteamine, (b) homocysteine, (c) glutathione. 
thiol investigated. The amperometric detection of glutathione is known to be usually achieved at very high potentials (i.e., ca. $1.0 \mathrm{~V}$ vs. $\mathrm{Ag} \mid \mathrm{AgCl}$ ) [41]. Prussian blue seems to act towards thiocholine, cysteamine and homocysteine oxidation using the first catalytic iron centre, which has a formal potential between 150 and $200 \mathrm{mV}$. This probably limits the use of Prussian blue to those thiols that are more easily oxidised.

\subsection{Thiol reactivity at PB modified electrodes}

To understand better the catalytic behaviour of Prussian blue towards thiol compounds, the amperometric response of a series of thiols has been evaluated at the potential chosen for thiocholine (i.e., 200 $\mathrm{mV}$ vs. $\mathrm{Ag} \mid \mathrm{AgCl})$ and the results are summarised in Table 1 .

Table 1

Different reactivities of PB modified SPE towards thiol compounds $\left(5 \times 10^{-4} \mathrm{~mol} \mathrm{l}^{-1}\right)$

\begin{tabular}{|c|c|c|}
\hline Analyte & Chemical formula & Signal $\left(\mu \mathrm{A} \mathrm{cm}^{-2}\right)$ \\
\hline Cysteamine (2-meracptoethylamine) & $\mathrm{HS}-\mathrm{CH}_{2}-\mathrm{CH}_{2}-\mathrm{NH}_{3}^{+}$ & 180.0 \\
\hline \multirow[t]{2}{*}{ Thiocholine } & $\mathrm{HS}-\mathrm{CH}_{2}-\mathrm{CH}_{2}-\mathrm{N}^{+}\left(\mathrm{CH}_{3}\right)_{3}$ & 48.3 \\
\hline & $\mathrm{OH}$ & \\
\hline Dithiothreitol (1,4-mercapto-2,3-butanediol) & $\begin{array}{c}\mathrm{HS}-\mathrm{CH}_{2}-\underset{\mathrm{O}}{\mathrm{OH}} \mathrm{C}-\mathrm{CH}-\mathrm{CH}_{2}-\mathrm{SH} \\
\end{array}$ & 16.9 \\
\hline L-Cysteine ethyl-ester & 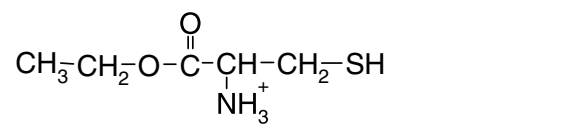 & 12.1 \\
\hline Propanthiol & $\mathrm{CH}_{3}-\mathrm{CH}_{2}-\mathrm{CH}_{2}-\mathrm{SH}$ & 7.5 \\
\hline Mercaptoethanol & $\mathrm{OH}-\mathrm{CH}_{2}-\mathrm{CH}_{2}-\mathrm{SH}$ & 5.7 \\
\hline Homocysteine & $\underset{\substack{\mathrm{NH}_{3}^{+} \\
{ }^{-\mathrm{O}}-\mathrm{C}-\mathrm{CH}}}{-\mathrm{CH}_{2}}-\mathrm{CH}_{2}-\mathrm{SH}$ & 5.6 \\
\hline Cysteine & $\underset{\substack{\mathrm{O} \\
-\mathrm{O}} \underset{\mathrm{N}}{\mathrm{C}} \mathrm{H}-\mathrm{H}_{3}^{+}}{\mathrm{C}}$ & 0.9 \\
\hline 2-Mercaptoimidazol & & 0.8 \\
\hline 6-Mercaptoesanol & $\mathrm{HO}-\left(\mathrm{CH}_{2}\right)_{6}-\mathrm{SH}$ & 0.6 \\
\hline$N$-acetylcysteine & $\begin{array}{c}\mathrm{O} \\
-\mathrm{O}-\mathrm{C}-\underset{\mathrm{C}}{\mathrm{CH}}-\mathrm{NH}-\stackrel{\mathrm{II}}{\mathrm{C}}-\mathrm{O}^{-} \\
\mathrm{CH}_{2} \\
\mathrm{I}_{2} \\
\mathrm{SH}\end{array}$ & 0 \\
\hline 1-Mercaptoundecanol & $\mathrm{HO}-\left(\mathrm{CH}_{2}\right)_{11}-\mathrm{SH}$ & 0 \\
\hline Mesna (2-mercaptoethane sulphonic acid) & $\mathrm{HS}-\mathrm{CH}_{2}-\mathrm{CH}_{2}-\mathrm{SO}_{3}^{-}$ & 0 \\
\hline Glutathione & $\begin{array}{l}-\mathrm{CH}_{1}-\mathrm{NH}-\mathrm{C}-\mathrm{CH}_{2}-\mathrm{CH}_{2}-\mathrm{CH}_{-} \mathrm{COO}^{-} \\
\mathrm{C}_{\mathrm{S}} \mathrm{CH}_{2} \\
\mathrm{~S}\end{array}$ & 0 \\
\hline 2-Nitro-4-mercaptobenzoic acid & $-\mathrm{COO}^{-}$ & 0 \\
\hline Mercaptopropionic acid & $\mathrm{HS}-\mathrm{CH}_{2}-\mathrm{CH}_{2} \stackrel{\mathrm{O}}{\mathrm{C}}-\mathrm{O}^{-}$ & 0 \\
\hline
\end{tabular}


Thiols that show the highest reactivity at $\mathrm{PB}$ modified electrodes are those that are positively charged at the $\mathrm{pH}$ used (cysteamine, thiocholine, L-cysteine ethyl ester). Thiols with a negative charge (cysteine, $N$-acetylcysteine) give a slight response, while in the case of glutathione, there is no response at all.

This effect of the negative charge on the reaction at the electrodes seems to be confirmed by analysis of the behaviour of cysteine, L-cysteine ethyl ester, and homocysteine. In the case of cysteine ethyl ester, in fact, the carboxylic group of cysteine is shielded by an ethyl group, and a more faciliated oxidation is observed (i.e., higher oxidation current). Cysteine ethyl ester is in fact almost 15 times more reactive at the PB modified electrode surface than cysteine. Moreover, in the case of cysteine, the carboxylic group is closer to the thiol group than in the case of homocysteine. This results in a 6-fold lower signal at the PB modified electrode. On the basis of these observations, it seems that molecules with a positively charged environment for the thiol are preferred over the negatively charged compounds for oxidation at the PB modified electrode surface.

In the case of high molecular mass molecules, the response at the PB modified electrode surface seems not to be dependent on the molecular charge and no detectable signal is observed for large molecules even at high concentration (i.e., mercaptoundecanol, glutathione). The effect of molecular size seems to be confirmed by the trend seen for $\beta$-mercaptoethanol, mercaptoesanol and mercaptoundecanol: with the increase in the carbon chain length, the response decreases until no response is observed.

Thiocholine and cysteamine are the thiols that are most reactive at the PB modified electrode surface. The importance of thiocholine for environmental analysis has already been mentioned, while the high reactivity of cysteamine could potentially be exploited via a disulphide interchange reaction to achieve an electrochemical tool for thiol detection.

For this reason the analytical parameters of the PB modified SPE for cysteamine and thiocholine detection have been fully evaluated and two applications are also presented in this work.

\subsection{Application}

\subsubsection{Amperometric measurements of thiols}

3.5.1.1. Cysteamine sensors. Table 2 shows data obtained for cysteamine amperometric detection at an applied potential of $200 \mathrm{mV}$ vs. $\mathrm{Ag} \mid \mathrm{AgCl}$. A detection limit (signal-to-noise ratio equal to 3 ) of $10^{-6} \mathrm{~mol}^{-1}$ together with a linear range up to $10^{-4} \mathrm{~mol}^{-1}$ has been achieved. The reproducibility $(\mathrm{RSD}=7 \%$ ) has been evaluated by studying the response to $5 \times 10^{-5} \mathrm{~mol} \mathrm{l}^{-1}$ of
Table 2

Analytical parameters of PB modified SPEs for thiocholine and cysteamine

\begin{tabular}{lll}
\hline Analyte & Thiocholine & Cysteamine \\
\hline Detection limit $\left(\mu \mathrm{mol} \mathrm{l}^{-1}\right)$ & 5.0 & 1.0 \\
Noise $\left.(\mathrm{nA} \mathrm{cm})^{-2}\right)$ & 57 & 43 \\
Linearity range $\left(\mathrm{mmol} \mathrm{l}^{-1}\right)$ & $5.0 \times 10^{-3}-0.5$ & $1.0 \times 10^{-3}-0.1$ \\
Sensitivity $\left(\mathrm{mA} 1 \mathrm{~mol}^{-1} \mathrm{~cm}^{-2}\right)$ & 143 & 452 \\
RSD $(\%)(n=5)$ & 7 & 6 \\
Time to reach stable & 60 & 60 \\
$\quad$ background $(\mathrm{s})$ & & 5 \\
Time to reach 90\% of the & 5 & \\
$\quad$ signal (s) & & \\
\hline
\end{tabular}

Batch amperometric analysis in stirred solution, applied potential $=200 \mathrm{mV}$ vs. $\mathrm{Ag} \mid \mathrm{AgCl} .0 .05 \mathrm{~mol} \mathrm{l}^{-1}$ phosphate buffer +0.1 mol $1^{-1} \mathrm{KCl}, \mathrm{pH} 7.4$.

cysteamine for five different sensors. Moreover, the response time is very short $(10 \mathrm{~s})$, as well as the time necessary to reach a stable background (30 s).

\subsubsection{Thiol measurements using a disulphide exchange} reaction. Although cysteamine has been found to have a very high reactivity at the $\mathrm{PB}$ modified electrode surface, its detection in clinical analysis is of limited use.

Among the compounds having clinical importance, glutathione (GSH), for example, represents more than $95 \%$ of the physiological thiols present in erythrocytes and the detection of glutathione is of great importance on account of its implication in a number of pathological conditions [37]. Homocysteine (Hcys) and cysteine (Cys) are involved in numerous important reactions as key extracellular reducing agents and perturbation in their concentration is commonly related to metabolic problems, for example, homocysteinuria [38] and to Alzheimer's and Parkinson's disease [39].

Moreover, some other thiols are widely used in the drug industry, the most important being $N$-acetylcysteine $(N$-acCys $)$ and penicillamine. The detection of these thiols might then be of importance in quality control processes.

However, for many of the thiols cited above (GSH, Cys, $N$-acCys and penicillamine) very low, and in some cases, no mediated oxidation at the PB modified electrodes was observed. Their detection has thus been achieved by use of an electrochemical alternative to Ellman's test which is based on the high reactivity of cysteamine at the PB modified SPE.

Ellman's test [40] is a widely used method which provides an accurate quantitative spectrophotometric measurement of thiols. It is based on the well-known disulphide exchange reaction between a thiol (RSH) and a disulphide (RSSR) (Eq. (3)):

$\mathrm{RSH}+\mathrm{R}^{\prime} \mathrm{SSR}^{\prime} \rightleftarrows \mathrm{R}^{\prime} \mathrm{SSR}+\mathrm{R}^{\prime} \mathrm{SH}$ 
In the Ellman test, the disulphide is DTNB (5,5'-dithiobis-(2-nitrobenzoic acid) and the sulphide produced in the reaction (Eq. (3)) is TNB having a yellow colour with a maximum adsorption at $412 \mathrm{~nm}(\varepsilon=13,600 \mathrm{~mol}$ $\left.1^{-1} \mathrm{~cm}^{-1}\right)$. In the presence of an excess of DTNB the reaction is very fast and a quantitative measure of thiol can be achieved.

In this work we used the oxidised form of cysteamine, cystamine (RSSR), to take part in the disulphide interchange reaction (Eq. (3)) and thus to provide an effective electrochemical alternative to the spectrophotometric Ellman method. Cystamine quickly reacts with reduced thiols $(\mathrm{RSH})$ to produce cysteamine, which is in turn detected amperometrically at the PB modified electrode surface. In Fig. 4 are shown the amperometric recordings obtained using this method. The cysteamine produced by the interchange reaction between cystamine and thiols is readily oxidised at the electrode surface. The reaction is complete in about $10 \mathrm{~min}$. At completion, the added thiol has totally undergone interchange with cystamine, producing an equal amount of cysteamine. The successive injection of a known concentration of cysteamine to the working solution can be a valuable tool to check the response of the electrode as a means for autocalibration. As shown in Fig. 4, for all the thiols tested, the response due to cysteamine is consistent with the concentration of thiol added. In a few cases (i.e., Cys and Hcys), the injection of thiol results in a low response due to the direct oxidation of these thiols at the electrode surface. In these cases it is sufficient to wait until the signal reaches a steady state (ca. $1 \mathrm{~min}$ ) before adding the excess of cystamine (RSSR).

This method seems to give promising results for both clinical or quality control analysis of thiols. It should be noted that using this procedure, the eventual presence of endogenous electroactive species such as

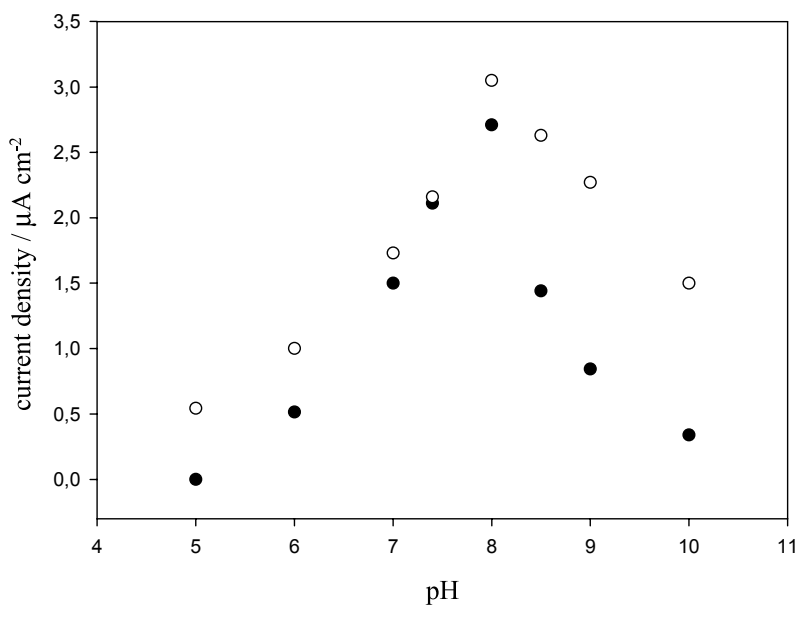

Fig. 5. pH effect on thiocholine signal (o) and acetycholinesterase ac-

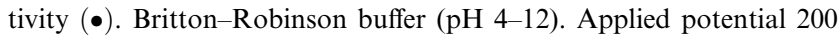
$\mathrm{mV}$ vs. $\mathrm{Ag} \mid \mathrm{AgCl}$. See text for details on thiocholine and acetylcholinesterase concentrations.

ascorbic acid, which is often present in biological samples, does not affect the output signal. In fact, any possible signal due to interfering species would appear in the new current background established before the injection of cystamine.

\subsubsection{Pesticide determination}

3.5.2.1. Thiocholine sensors. The analytical data obtained in batch $(10 \mathrm{ml})$ amperometric system measurement of thiocholine standard solutions are summarised in Table 2. A detection limit $(\mathrm{S} / \mathrm{N}=3)$ of $5 \times 10^{-6} \mathrm{~mol}$ $1^{-1}$ together with a linear range up to $5 \times 10^{-4} \mathrm{~mol} \mathrm{l}^{-1}$ has been reached. The reproducibility has been evaluated by studying the response to $10^{-4} \mathrm{~mol}^{-1}$ of thiocholine for five different sensors. The measurement of

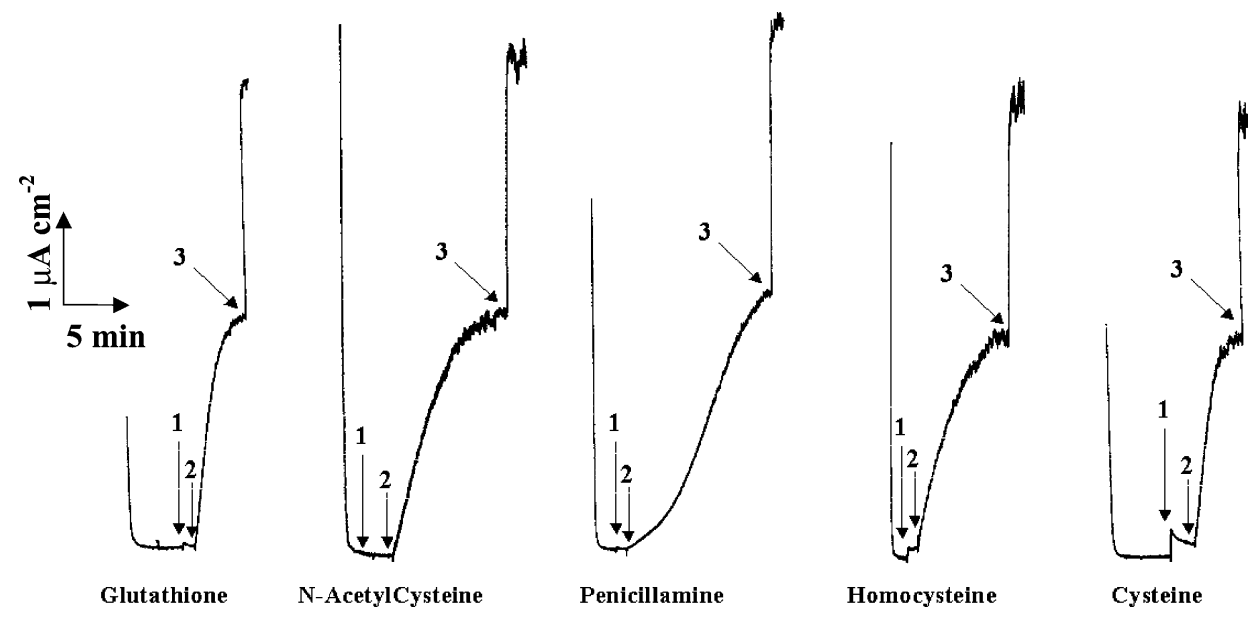

Fig. 4. Original recordings obtained with the electrochemical alternative to Ellman's test for glutathione, $N$-acetylcysteine, penicillamine, homocysteine, cysteine: PB modified SPEs were used in batch amperometric mode $(200 \mathrm{mV}$ vs. $\mathrm{Ag} \mid \mathrm{AgCl})$ in stirred solution. Known amounts $\left(2 \times 10^{-5}\right.$ $\left.\mathrm{mol} \mathrm{l}^{-1}\right)$ of thiol were added as indicated by the 1st arrows. Cystamine (RSSR) $\left(1 \times 10^{-3} \mathrm{~mol}^{-1}\right)$ was then added (second arrow). A control of cysteamine $\left(2 \times 10^{-5} \mathrm{~mol}^{-1}\right)$ was added after a stable baseline was reached (third arrow). 

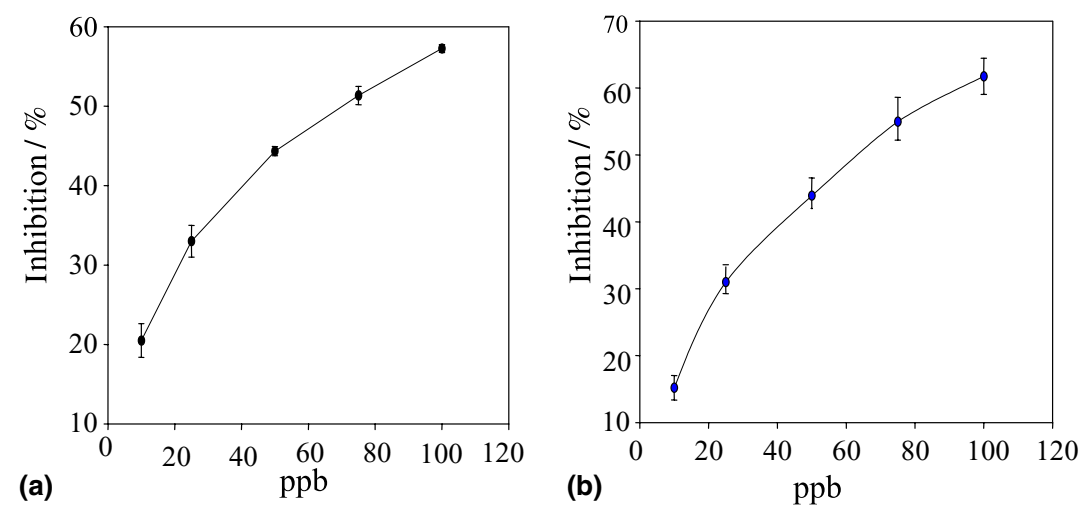

Fig. 6. Calibration plots for Paraoxon (a) and Aldicarb (b) standard solutions. $0.05 \mathrm{~mol} \mathrm{l}^{-1}$ phosphate buffer $+0.1 \mathrm{~mol} \mathrm{l}^{-1} \mathrm{KCl}$, $\mathrm{pH} 7.4$. Acetylcholinesterase concentration $=2.0 \mathrm{mU} / \mathrm{ml}$. Incubation time $=10 \mathrm{~min}$. Acetylthiocholine added $=2 \times 10^{-3} \mathrm{~mol}^{-1}$ and signal recorded $20 \mathrm{~min}$ after the injection. Applied potential $=200 \mathrm{mV}$ vs. $\mathrm{Ag} \mid \mathrm{AgCl}$.

thiocholine was then used for the detection of pesticides by determining the residual activity of acetylcholinsterase, which catalyzes the following reaction:

Acetylthiocholine $\stackrel{\mathrm{H}_{2} \mathrm{O}, \mathrm{AChE}}{\longrightarrow}$ Thiocholine + Acetic Ac

In this work the acetylcholinesterase (AchE) was used free in solution and parameters such as working $\mathrm{pH}$, enzyme concentration were evaluated in order to achieve the best sensitivity for pesticides.

3.5.2.2. Choice of the working $\mathrm{pH}$. The working $\mathrm{pH}$ was chosen, considering both the signal of the PB modified SPE to thiocholine and the activity of acetycholinesterase as a function of $\mathrm{pH}$.

First the thiocholine $\left(10^{-5} \mathrm{~mol} \mathrm{l}^{-1}\right)$ response was measured at $200 \mathrm{mV}$ vs. $\mathrm{Ag} \mid \mathrm{AgCl}$ in a $\mathrm{pH}$ range between 5 and 10, using a Britton-Robinson universal buffer which was suitable for all the $\mathrm{pH}$ values tested. These results are shown in Fig. 5.

To evaluate the enzyme activity as a function of $\mathrm{pH}$, the acetycholinesterase concentration used was $0.2 \mathrm{U} /$ $\mathrm{ml}$, the concentration of acetylthiocholine added was $2 \times 10^{-4} \mathrm{~mol} \mathrm{l}^{-1}$ and the current due to the formation of thiocholine was recorded after $10 \mathrm{~min}$. The signals obtained are shown in Fig. 5. At pH values between 7 and 8 we observed the highest activity of acetylcholinesterase with a rapid decrease above $\mathrm{pH}$ 8.0. The signal of thiocholine showed a maximum at $\mathrm{pH} 8$ and only slight variations were recorded at $\mathrm{pH} 7.4$ and 8.5. Thus, a $\mathrm{pH}$ of 7.4 was chosen for further experiments.

3.5.2.3. Inhibition measurements. Measurements were carried out using standard solutions of both an organophosphorous (i.e., Paraoxon) and a carbammic (i.e., Aldicarb) pesticide over a concentration range of 10-100 ppb. The enzyme concentration selected (i.e., $2.0 \mathrm{mU} /$ $\mathrm{ml}$ ) was the lowest concentration giving a defined detectable signal for thiocholine after $20 \mathrm{~min}$ from the addition of acetylthiocholine $\left(2 \times 10^{-3} \mathrm{~mol}^{-1}\right) .10 \mathrm{~min}$ of incubation time was then selected as a good compromise between the need for a rapid measurement and a high degree of inhibition.

In Fig. 6 the two calibration plots obtained for Paraoxon and Aldicarb are shown. The detection limits, defined in this work as the concentrations giving an inhibition of $20 \%$, were 9 and $13 \mathrm{ppb}$, respectively. Measurements were replicated four times and an average RSD of 7\% was obtained for both pesticides. By increasing the incubation time up to $30 \mathrm{~min}$, an increase in the degree of inhibition could be observed and lower detection limits for both Aldicarb (5 ppb) and Paraoxon (3 ppb) were achieved.

These analytical performances are similar to those of both the bienzymatic and monoenzymatic biosensors [42-44]. In comparison with standard analysis methods (GC-HPLC), our procedure seems to be suitable for a time effective in situ analysis that can allow a prescreening test.

\section{Conclusions}

The electrocataytic behaviour of Prussian blue modified screen-printed electrodes was investigated by use of both cyclic voltammetry and amperometric experiments. The measurement of thiocholine and cysteamine at low applied potentials (i.e., $200 \mathrm{mV} / \mathrm{s}$ ) was performed in amperometric batch mode. Detection limit of $5 \times 10^{-6}$ mol $1^{-1}$ and $10^{-6} \mathrm{~mol}^{-1}$, respectively, were found. The amperometric signal at the same applied potential was also evaluated for many thiocompounds in order to elucidate the catalytic mechanism at the Prussian blue modified electrode surface.

Cysteamine measurements were used in an electrochemical alternative to the Ellman test. Standard solutions of glutathione, cysteine, $N$-acetylcysteine, penicillamine and homocysteine were assayed and the results are promising as to future clinical or pharmaceutical applications. 
Finally, pesticide detection was demonstrated by means of thiocholine determination to monitor acetylcholinesterase inhibition. Aldicarb and Paraoxon were chosen as sample standard pesticides and detection limits as low as 9 and $13 \mathrm{ppb}$, respectively, were demonstrated.

\section{Acknowledgements}

Thanks are due to the INBB (Istituto Nazionale di Biostrutture e Biosistemi) for financial support.

\section{References}

[1] P.C. White, N.S. Lawrence, J. Davids, R.G. Compton, Electroanal. 14 (2002) 89.

[2] A. Meister, Science. 220 (1983) 472.

[3] C. Ceconi, A. Curello, A. Carnioni, R. Ferrari, A. Albertini, O. Visioli, J. Mol. Cell. Cardiol. 20 (1988) 5

[4] T.B. Breithaupt, A. Vazquez, I. Baez, E.H. Eylar, Cell. Immunol. 173 (1996) 124.

[5] M. Stachowicz, B. Lehmann, A. Tibi, P. Prognon, V. Daurat, D. Pradeau, J. Pharm. Biomed. Anal. 17 (1998) 767.

[6] R.P. Baldwin, M.K. Halbert, Anal. Chem. 57 (1985) 591.

[7] R.P. Baldwin, M.K. Halbert, J. Chromatogr. Biomed. 345 (1985) 43.

[8] S.A. Wring, J.P. Hart, B.J. Birch, Analyst. 116 (1991) 123.

[9] T. O'Shea, S.M. Lunte, Anal. Chem. 66 (1994) 307.

[10] S.A. Wring, J.P. Hart, B.J. Birch, Electroanal. 4 (1992) 299.

[11] X. Huang, W.T. Kok, Anal. Chim. Acta 273 (1993) 245.

[12] J. Wang, P.V.A. Pamidi, C. Parrado, D.S. Park, J. Pingarron, Electroanal. 9 (1997) 908.

[13] T.R.I. Cataldi, G.E. De Benedetto, A. Bianchini, Electroanal. 10 (1998) 1163

[14] A. Eftekhari, J. Electroanal. Chem. 537 (2002) 59.

[15] D.R. Shankaran, S.S. Narayanan, Sensor. Actuat. B 86 (2002) 180.

[16] S.M. Chen, J. Electroanal. Chem. 417 (1996) 145.

[17] S. Zhang, W. Sun, W. Zhang, W. Qi, L. Jin, K. Yamamoto, S. Tao, J. Jin, Anal. Chim. Acta 386 (1999) 21.
[18] J. Zen, P. Chen, A.S. Kumar, Electroanal. 14 (7-8) (2002) 513.

[19] E. Wilkins, M. Carter, J. Voss, D. Ivnitski, Electrochem. Commun. 2 (2000) 786.

[20] K. Itaya, H. Akahoshi, V.D. Neff, J. Phys. Chem. 85 (1981) 1225.

[21] A.A. Karyakin, E.E. Karyakina, L. Gorton, J. Electroanal. Chem. 456 (1998) 97.

[22] D. Moscone, D. D’Ottavi, D. Compagnone, G. Palleschi, A. Amine, Anal. Chem. 73 (2001) 2529.

[23] F. Ricci, A. Amine, G. Palleschi, D. Moscone, Biosens. Bioelectron. 18 (2003) 165.

[24] R. Garjonyte, Y. Yigzaw, R. Meskys, A. Malinauskas, L. Gorton, Sensor. Actuat. B 79 (2001) 33.

[25] R. Garjonyte, A. Malinauskas, Sensor. Actuat. B 46 (1998) 236.

[26] M.P. O’Halloran, M. Pravda, G.G. Guilbault, Talanta 55 (2001) 605.

[27] F. Ricci, G. Palleschi, Y. Yigzaw, L. Gorton, T. Ruzgas, A.A. Karyakin, Electroanal. 15 (2003) 175.

[28] A.A. Karyakin, E.E. Karyakina, L. Gorton, Anal. Chem. 72 (2000) 1720

[29] K. Itaya, N. Shoji, I. Uchida, J. Am. Chem. Soc. 106 (1984) 3423.

[30] Q. Chi, S. Dong, Anal. Chim. Acta 310 (1995) 429.

[31] M. Alvarez-Icaza, U. Bilitewski, Anal. Chem. 65 (1993) 525A.

[32] J. Hart, S. Wring, Electroanal. 6 (1994) 617.

[33] C. Galan-Vidal, J. Munoz, C. Domingez, S. Alegret, TrAC Trend. Anal. Chem. 14 (1995) 225.

[34] S. Kroger, A.P.F. Turner, Anal. Chim. Acta 347 (1997) 9.

[35] A. Cagnini, I. Palchetti, I. Lionti, M. Mascini, A.P.F. Turner, Sensor. Actuat. B 24 (1995) 85.

[36] A.A. Karyakin, Electroanal. 13 (10) (2001) 813.

[37] W.A. Kleinman, J.P. Richie, Biochem. Pharmacol. 60 (2000) 19.

[38] H. Mudd, H.L. Levy, F. Skovby, in: C.R. Scriver, A.L. Beaudet, W.S. Sly, D. Valle (Eds.), The Metabolic and Molecular Basis of Inherited Disease, McGraw-Hill, New York, 1995, pp. 1279-1327.

[39] M.T. Eafield, S. Fearn, G.B. Steventon, R.H. Waring, A.C. Sturman, Neurosci. Lett. 24 (1998) 699.

[40] G.L. Ellman, Arch. Biochem. Biophys. 82 (1959) 70.

[41] P.J. Vandeberg, D.C. Johnson, Anal. Chem. 65 (1993) 2713.

[42] N. Jaffrezic-Renault, Sensors 1 (2001) 60.

[43] S. Hernandez, I. Palchetti, M. Mascini, Int. J. Environ. Anal. Chem. 78 (2000) 263.

[44] M. Albareda-Sirvent, A. Mercoçi, S. Alegret, Sensor. Actuat. B 69 (2000) 153. 